\title{
Spectrophotometric and Reverse Flow Injection Method Determination of Nitrazepam in Pharmaceuticals Using O-Coumaric Acid as a New Chromogenic Reagent
}

\author{
Sadeem Subhi Abed
}

Received 4/3/2019, Accepted 8/10/2019, Published 18/3/2020

(-)

This work is licensed under a Creative Commons Attribution 4.0 International License.

\begin{abstract}
:
A spectrophotometric- reverse flow injection analysis ( $\mathrm{rFIA}$ ) method has been proposed for the determination of Nitrazepam (NIT) in pure and pharmaceutical preparations. The method is based upon the coupling reaction of NIT with a new reagent O-Coumaric acid (OCA) in the presence of sodium periodate in an aqueous solution. The blue color product was measured at $632 \mathrm{~nm}$. The variation (chemical and physical parameters) related with reverse flow system were estimated. The linearity was over the range $15-450$ $\mu \mathrm{g} / \mathrm{mL}$ of NIT with detection limits and limit of quantification of 3.425 and $11.417 \mu \mathrm{g} \mathrm{mL}$ NIT,respectively. The sample throughput of 28 samples per hour was achieved. Suggested method was successfully applied for the determination of NIT in its dosage forms.
\end{abstract}

Key words: Chromogenic reagent, Nitrazepam, O- Coumaric acid, Reverse flow injection method

\section{Introduction:}

Nitrazepam (NIT) (7-nitro-5-phenyl-1Hbenzo[e][1,4]diazin-2(3H)-one, $M . \quad$ wt. $=281.3$ $\mathrm{g} / \mathrm{mol}$ ), is a hypotic agent that belongs to the benzodiapine class. NIT is used for healing the sedative effects of insomnia (1), as well as anxiolytic, amnestic, anticovulsant and skeletal muscle relaxant properties. In addition, it has been used in the treatment of stress associated with disorders (2,3). Nitrazepam chemical structure contains an important nitro group (Fig.1). Nitro group plays an important function in the action of these drugs, and the nitro group or even other electron attracting functional is necessary for specific desired biological effect.<smiles>O=C1CN=C(c2ccccc2)c2cc([N+](=O)[O-])ccc2N1</smiles>

Figure 1. Nitrazepam chemical structure $\left(\mathrm{C}_{15} \mathrm{H}_{11} \mathrm{~N}_{3} \mathrm{O}_{3}\right)$

Department of Chemistry, College of Science, University of Baghdad, Baghdad, Iraq

E-mail: sadeem.s@sc.uobaghdad.edu.iq

*ORCID ID:0000-0001-9606-1972
Different methods have been reported for NIT determination in various samples, including silver nanoparticle enhanced chemiluminescence method (4), liquid-liquid micro-extraction followed by HPLC (5), RP-HPLC(6), UFLC- mass spectrometry (7), capillary electrophoresis(8), multi wavelength spectrophotometry (9), micellar electrokinetic capillary chromatography (10), thin layer chromatography-densitometry(11), gas chromatography-mass spectrometry(12), and HPLC-voltammetry(13). Also various spectrophotometric methods have been reported for determination of NIT, after reduction by $\mathrm{Zn} / \mathrm{HCl}$, such as coupling with different reagents namely, $\mathrm{N}$ (1-napthyl)-ethylene diamine dihydrochloride(14), m-aminophenol(15), acetyl acetone(16), vanillin (17), Metol (18), and phloroglucinol(19). Among the different techniques, the spectrophotometric and flow injection analysis methods are considered the most popular and simple methods existing for quick and trace analysis of different pharmaceutical forms (20-22). One of the flow injection analysis modes is reverse flow injection analysis (rFIA), in which the reagent is injected into the sample stream which is reversed to the usual FIA when the sample is injected. The main advantages of rFIA mode are the minimization of reagent consumption and waste disposal, improving the analytical sensitivity by enhancing mixing efficiency, and the possibility of making several different determination on the same 
sample solution stream by injection of different reagents $(23,24)$.

The present investigation method offers an improvement of the simple spectrophotometric-rFI technique for the estimation of NIT in both pure and pharmaceutical forms as tablet depending on the oxidative coupling reaction between NIT and OCoumaric acid as a new chromogenic agent in the presence of sodium periodate in an aqueous medium to produce a blue-colored product.

\section{Materials and Methods:} Tools

-A Shimadzu UV-VIS 260 double beam spectrophotometer (Shimadzu, Kyoto-Japan) had been used for absorbance measurements in FIA procedure. The absorbance measurements were carried out using $1 \mathrm{~cm}$ path length of quartz flow matched cells (Cecil, $50 \mu \mathrm{L}$ internal volume).

- A peristaltic pump of six channels (SHENCHEN, CHINA) was used for impelling the reagents and sample solutions using flexible polyvinyl chloride tubes of ( $0.8 \mathrm{~mm}$ i.d.).

- The injection valve of 6 - ways (KNAUER, Germany) with various sample loops was used to injected sample solutions.

- Flexible Teflon tubes of $(0.5 \mathrm{~mm}$ i.d.) were used for reaction coils with different lengths. And T links were used to mix streams of reagents.

For rFIA a two-channel manifold was used (Fig. 2), first channel used to transported the solution of (NIT). And the second channel was used to flow sodium periodate solution, while the reagent $\mathrm{O}-$ Coumaric acid (OCA) was injected through the injected valve then it was mixed with the stream of drug and oxidant and the mixing completed in the reaction coil. The blue colored was measured at 632 $\mathrm{nm}$.

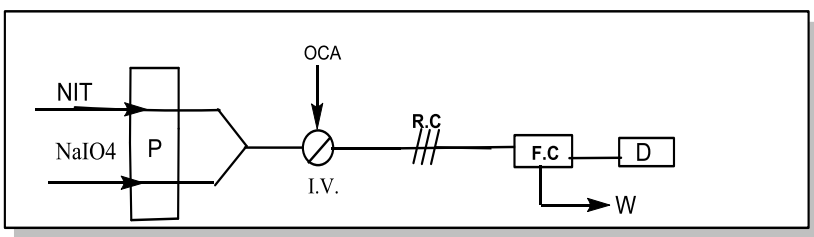

Figure 2. The manifold used for rFIA method for determination of NIT by reaction with OCA in presence of $\mathrm{NaIO4}$, where: $\mathrm{IV}$, injection velve; $R C$, reaction coil; $P$, peristaltic pump; FC, flow cell; $D$, detector; $W$, waste.

\section{Chemicals and Reagents}

All chemicals used were analytical grade reagents, and distilled water was used for the work. NIT Pharmaceutical grade was supplied from SDI, Samara-Iraq. Pharmaceutical dosage forms containing NIT (Zipex® 5 mg, Aburaihan Pharmaceutical Co., Tehran, Iran) were obtained from local commercial sources.

\section{NIT Solution $\left(500 \mu \mathrm{g} \mathrm{mL^{-1 } )}\right.$}

The reduction solution of NIT was prepared by dissolving $0.0500 \mathrm{~g}$ of NIT in $50 \mathrm{~mL}$ of ethanol. Then it was transferred into a beaker and $20 \mathrm{~mL}$ of distilled water, $20 \mathrm{~mL}$ of $11.65 \mathrm{~N}$ hydrochloric acid, and $3.0 \mathrm{~g}$ of zinc powder were added. The mixture was allowed to stand for about $15 \mathrm{~min}$ at room temperature $\left(25^{\circ} \mathrm{C}\right)$. The solution was filtered into a $100 \mathrm{~mL}$ volumetric flask, and the residues were washed and diluted to the mark with D.W. Simple dilution was used daily to prepare further diluted solutions.

\section{OCA Solutions $(0.05 \mathrm{M})$}

The solution was prepared daily by diluting $0.8220 \mathrm{~g}$ of OCA with $100 \mathrm{~mL}$ of D.W and then transferred into brown bottle for keeping it out from light. The diluting solutions were prepared with distilled water.

\section{Sodium Periodate $\mathrm{NaIO}_{4}(0.03 \mathrm{M})$}

This solution was prepared by diluting $0.6416 \mathrm{~g}$ of $\mathrm{NaIO}_{4}$ with100 mL D.W. Working solutions was prepared by suitable dilution by using the same solvent.

\section{Pharmaceutical Solutions}

10 tablets were accurately weighed and powdered. Then, an amount of powder equivalent to $50 \mathrm{mg}$ of NIT was dissolved in approximately 30 $\mathrm{mL}$ of ethanol. This solution was filtered into a 50 $\mathrm{mL}$ volumetric flask and then washed and diluted to the mark with ethanol to obtain $500 \mu \mathrm{g} \mathrm{mL}^{-1}$ of NIT. The resultant solution was transferred into $125 \mathrm{~mL}$ beaker and was reduced as described above. The appropriately diluted solutions of the medicinal formulations were made with distilled water.

\section{Results and Discussion: Preliminary studies}

The absorption spectra of the product and the blank were obtained. In a $10-\mathrm{mL}$ volumetric flask a $25 \mu \mathrm{g} \mathrm{mL}^{-1}$ concentration of reduced NIT, 1 $\mathrm{mL}$ of $0.05 \mathrm{M}$ of OCA, and $2 \mathrm{~mL}$ of $0.03 \mathrm{M} \mathrm{NaIO}_{4}$ were mixed and the blue -colored product was formed immediately. The flasks were made up to the mark with distilled water. The absorption spectra were recorded between 380 and $1000 \mathrm{~nm}$. The maximum value of absorption was dignified at $632 \mathrm{~nm}$ versus the reagent blank (Fig. 3). 


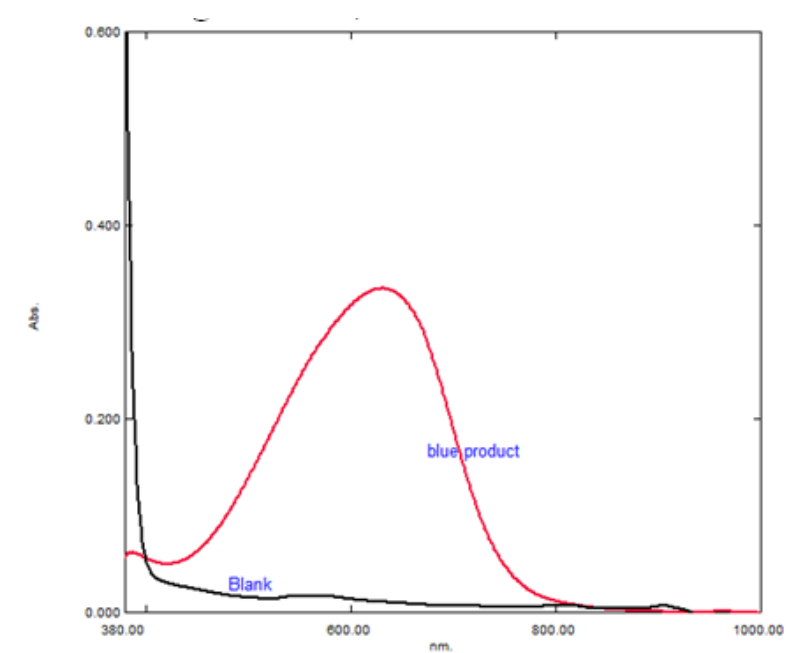

Figure 3. The absorbance spectrum of blue colored product of $25 \mu \mathrm{g} \mathrm{mL}^{-1}$ of NIT measured versus reagent blank, and the blank versus D.W

After studying the reaction stoichiometry of reaction in a batch method using an equimolar<smiles>NN1C(=O)CN=C(c2ccccc2)c2cc([N+](=O)[O-])ccc21</smiles><smiles>Nc1ccc2c(c1)C(c1ccccc1)=NCC(=O)N2</smiles>

concentration of NIT and OCA (0.00177M for both) and applying the mole ratio method and jobs method, it was found that a 1:1 NIT: OCA ratio was obtained. The mechanism of the reaction was summarized by reduction the nitro group of NIT compound in first step (using zinc powder with concentrated $\mathrm{HCl}$ ) followed by oxidative coupling between reduced drug and OCA in the presence of $\mathrm{NaIO}_{4}$ as oxidizing agent (25) as shown in Scheme1.The conditional stability constant of the blue colored product was $2914.092 \mathrm{M}^{-1}$. The Gibbs free energy $(\Delta G)(26)$ of the reaction was also determinate to indicate the spontaneously of the reaction $\Delta \mathrm{G}$ was calculated using the equation $(\Delta \mathrm{G}=-2.303 \mathrm{RT} \log \mathrm{K})$, where $\mathrm{T}$ is the absolute temperature $\left(273+25^{\circ} \mathrm{C}\right), \mathrm{R}$ is the universal gas constant $(19.767 \mathrm{~J} / \mathrm{mol} \mathrm{k})$. The negative value of $\Delta \mathrm{G}$ refers to the spontaneously of the current reaction.
NIT<smiles>O=C(O)/C=C/c1ccccc1Nc1ccc2c(c1)C(c1ccccc1)=NCC(=O)N2</smiles>

\section{Shceme1. The probable reaction mechanism}

Optimization of rFIA System (Chemical and Physical Parameters)

In order to enhance the conditions of the method, preliminary studies were directed toward optimization of the experimental conditions, so as to select the most favorable parameters for the reaction, the absorbance was measured at a wavelength of $632 \mathrm{~nm}$ against reagent blank. The preliminary chemical and physical parameters are listed in Table1; the reagent was injected three times for each experiment. 
Table 1. The preliminary experimental conditions for proposed rFIA

\begin{tabular}{cc}
\hline Parameters & Value \\
\hline Conc. of NIT & $100 \mu \mathrm{mL}^{-1}$ \\
Conc. of OCA & $0.003 \mathrm{M}$ \\
Conc. of NaIO & $0.01 \mathrm{M}$ \\
Total flow rate & $2.0 \mathrm{~mL} / \mathrm{min}$ \\
Sample loop & $100 \mu \mathrm{L}$ \\
Reaction coil & $50 \mathrm{~cm}$ \\
\hline
\end{tabular}

\section{Effect of Chemical Parameters}

Different concentrations of the reagent (OCA) was injected (from 0.0005 to $0.15 \mathrm{M}$ ) to choose the best concentration of the reagent. The results indicated that the concentration of $0.005 \mathrm{M}$ of OCA offered the highest absorbance (Fig. 4). Different concentration of sodium periodate was also studied and optimized using the concentration range between $(0.005$ to $0.06 \mathrm{M})$, the concentration of $0.03 \mathrm{M}$ showed the higher absorbance and therefore, it was used in all subsequent experiments (Fig. 5).

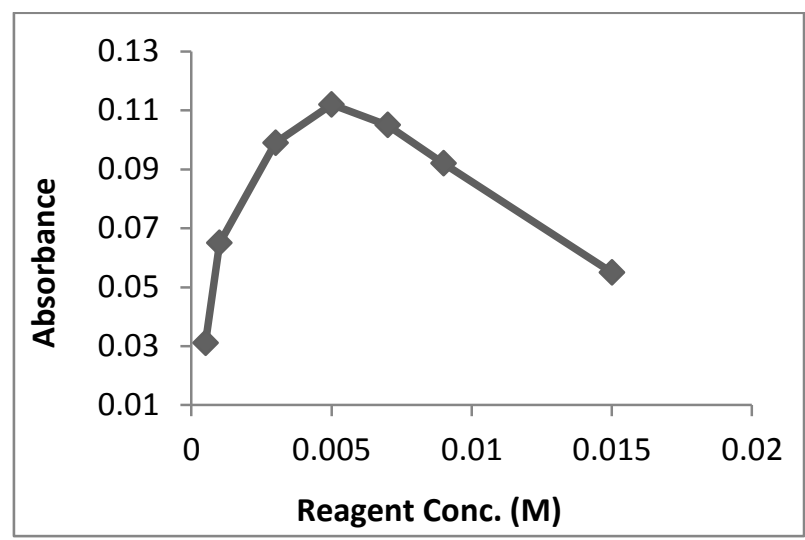

Figure 4. Effect of the concentration of reagent

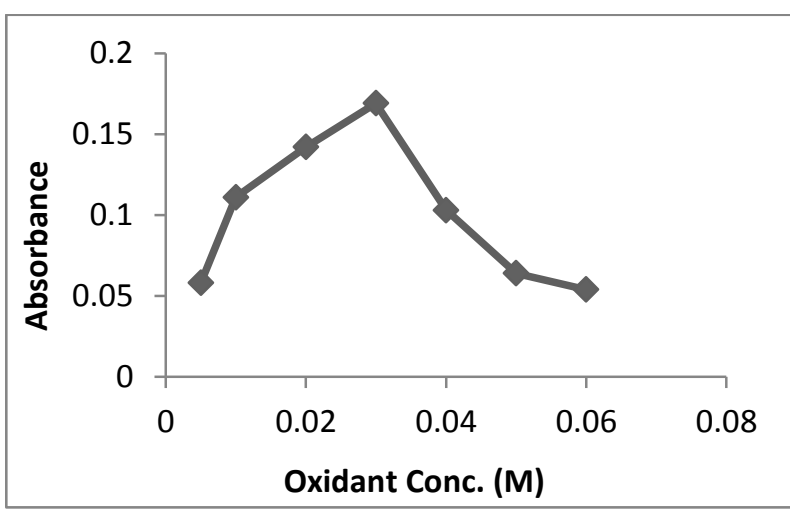

Figure 5. Effect of the concentration of oxidant

\section{Effect of Physical Parameters}

The reaction coil lengths effect was examined using variable reaction coils lengths ranged from 0(i.e. without reaction coil) to $250 \mathrm{~cm}$ and as shown in Fig. 6, the maximum absorbance and good repeatability were obtained when reaction coil length of $150 \mathrm{~cm}$ used. The higher length of reaction coils caused an increase in the dispersion.

The flow rate between 0.4 and $4.1 \mathrm{~mL} / \mathrm{min}$ was also studied. As the flow rate increased, the absorbance also increased up to $1.8 \mathrm{~mL} / \mathrm{min}$ (Fig. 7). Increasing the flow rate leads to the absorbance decrease, and this can be attributed to the dispersion. As a result, $1.8 \mathrm{~mL} / \mathrm{min}$ was selected as the optimum rate.

The injected reagent volume was examined by varying the sample loop in the range from $75-250$ $\mu \mathrm{L}$. Above $100 \mu \mathrm{L}$, the absorbance decreased due to the high reagent to sample volume ratio which leads to insufficient ratio and the sample loop of $100 \mu \mathrm{L}$ was the optimum loop in this work and it was used in further experiments (Fig. 8).

The sampling rate was calculated by recording the period from the injected instant to the appearance of maximum absorbance. The sampling frequency under the optimum conditions (Table 2) was 28 sample per hour (128 second for each sample).

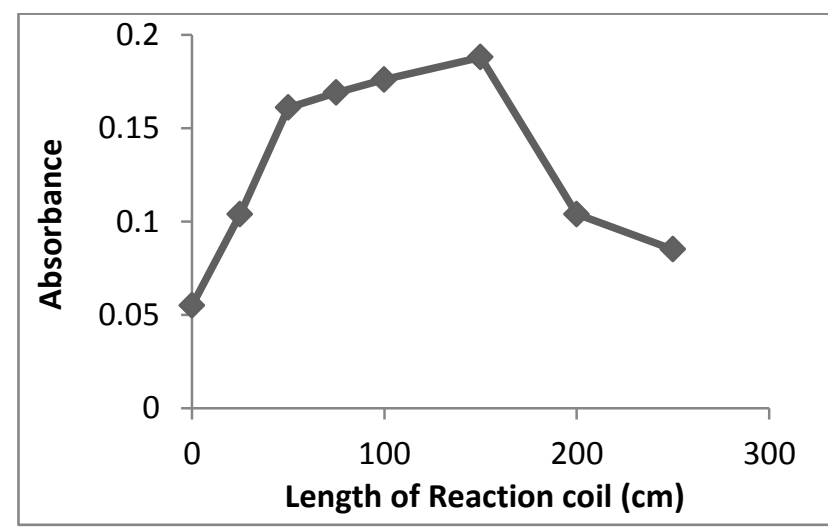

Figure 6. Effect of the reaction coil length

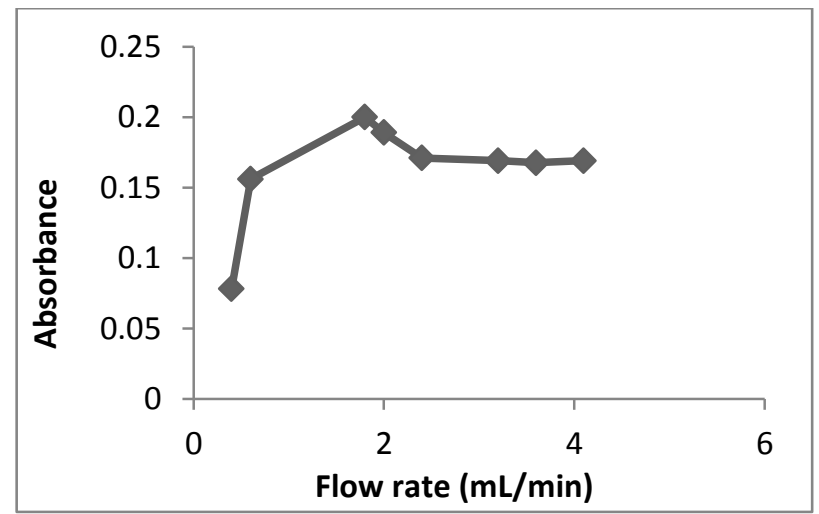

Figure 7. Effect of the total flow rate 


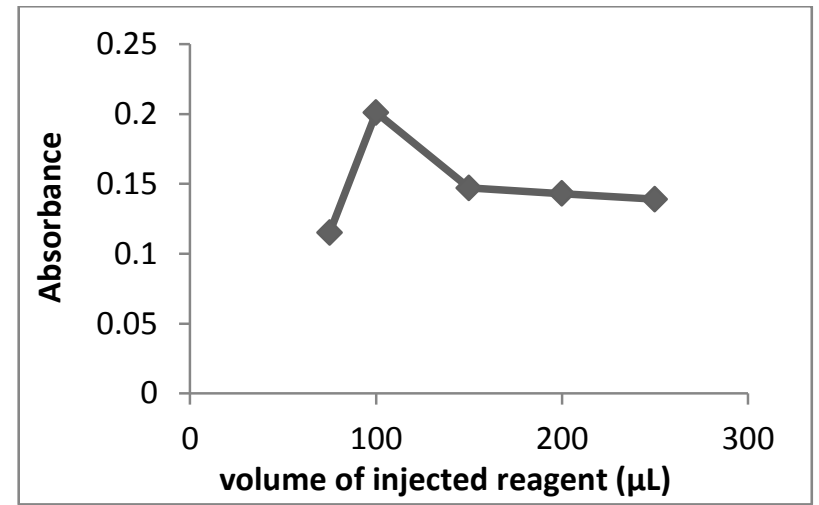

Figure 8. Effect of the volume of injected reagent

Table 2. The optimum experimental conditions for the proposed rFIA system

\begin{tabular}{cc}
\hline Parameters & Value \\
\hline Conc. of OCA & $0.005 \mathrm{M}$ \\
${\text { Conc. of } \mathrm{NaIO}_{4}}_{\text {Total flow rate }}$ & $0.03 \mathrm{M}$ \\
Sample loop & $1.8 \mathrm{~mL} / \mathrm{min}$ \\
Reaction coil & $100 \mu \mathrm{L}$ \\
\hline
\end{tabular}

\section{Calibration Curve, Limit of Detection ,} Accuracy and Precision

A linear calibration curve was achieved over the range $15-450 \mu \mathrm{g} \mathrm{mL} \mathrm{m}^{-1}$ of NIT with a limit of detection (LOD) of $3.425 \mu \mathrm{g} \mathrm{mL}^{-1}$ and limit of quantification (LOQ) of $11.417 \mu \mathrm{g} \mathrm{mL}^{-1}$ under the optimal conditions. Table 3 summarizes the statistical analytical treatments for the curve and analytical values, the value of correlation coefficient indicated the high linearity of the suggested method.

To establish the accuracy and precision of the suggested rFIA technique, three different concentrations (five replicates) of NIT were analyzed. The small values of RSD\% and Erel\% indicated that the method provided good accuracy and repeatability (Table 4).

Table 3. Statistical analysis and analytical data of the calibration curve of NIT.

\begin{tabular}{|c|c|}
\hline Parameter & Value \\
\hline Regression equation & $y=0.0015 x-0.0501$ \\
\hline Slope, $b\left(\mu \mathrm{g} \mathrm{mL}^{-1}\right)$ & 0.0015 \\
\hline Intercept, a & 0.050115 \\
\hline Correlation coefficient, $r$ & 0.9996 \\
\hline Linearity percentage, $\mathrm{r}^{2} \%$ & 99.92 \\
\hline Linearity range $\left(\mu \mathrm{g} \mathrm{mL}^{-1}\right)$ & $15-450$ \\
\hline$S_{b}$, standard deviation of the slope & 0.0000125 \\
\hline $\begin{array}{l}\mathrm{S}_{\mathrm{a}} \text {, standard deviation of the } \\
\text { intercept }\end{array}$ & 0.00291337 \\
\hline $\begin{array}{l}S_{y / x} \text {, standard deviation of the } \\
\text { residuals }\end{array}$ & 0.005966 \\
\hline Limit of quantification, $\left(\mu \mathrm{g} \mathrm{mL}^{-1}\right)$ & $\underline{11.417}$ \\
\hline $\begin{array}{l}\left.\text { Limit of detection, } \mu \mathrm{g} \mathrm{mL}^{-1}\right) \\
\hat{y}=\mathrm{y}_{B}+3 \mathrm{SD}_{\mathrm{B}}\end{array}$ & $\overline{0.0215}$ \\
\hline Limit of detection, $\left(\mu \mathrm{g} \mathrm{mL}^{-1}\right)$ & 3.425 \\
\hline Sandell's sensitivity, $\mathrm{S}\left(\mu \mathrm{g} \mathrm{cm}^{-2}\right)$ & 0.6666 \\
\hline Sample frequency (sample/hour) & 28 \\
\hline
\end{tabular}

Table 4: the precision and accuracy of the rFIA suggested method.

\begin{tabular}{|c|c|c|c|c|}
\hline \multicolumn{2}{|c|}{ Conc. of NIT $\mu \mathrm{g} \mathrm{mL}^{-1}$} & \multirow{2}{*}{ Erel \% } & \multirow[b]{2}{*}{ Rec. \% } & \multirow[b]{2}{*}{ RSD \% } \\
\hline Present & Found* & & & \\
\hline 50 & 50.6000 & +1.200 & 101.200 & 1.2548 \\
\hline 100 & 101.2667 & -1.2667 & 101.266 & 1.8850 \\
\hline 250 & 247.2667 & -1.0933 & 98.906 & 0.5311 \\
\hline
\end{tabular}

*Average of five determinations

To assess the efficiency of the method and avoid the restrictions from interference by tablet additives, the determinate of NIT was accomplished by using the standard addition method at two different concentration and the results in Table 5 indicated the high accuracy and precision of the method.

Table 5. The accuracy and precision using standard addition method

\begin{tabular}{ccccccc}
\hline \multirow{2}{*}{ Pharmaceutical form } & \multicolumn{2}{c}{ Conc. of NIT $\boldsymbol{\mu g} \mathbf{~ m L}^{-\mathbf{1}}$} & \multirow{2}{*}{ Erel \% } & \multirow{2}{*}{ Rec. \% } & RSD \% \\
\cline { 2 - 3 } & Present & Found $^{*}$ & & +1.400 & 99.400 & 2.467 \\
Zipex® tablets (5 mg NIT & 100 & 101.400 & & -1.778 & 98.222 & 0.998 \\
\hline
\end{tabular}

*Average of five determinations

\section{Analytical Applications}

The rFIA method was effectively applied for the determination of NIT in commercial pharmaceuticals by the analysis of two different concentrations directly, and the results are given in Table 6. The recoveries of NIT were between 100.693 to $101.137 \%$ which revealed that the current method is accurate and the relative standard deviation was between 0.636 to $1.504 \%$ which revealed that the current method is repeatable for the determination of NIT in commercial pharmaceuticals. The results obtained from the suggested method were in comparison with those obtained by applying the standard method (UV 
method) (1).The results of the recovery test were compared with those resulting from using classical UV-method (1) using "Student's $t$-test and (variance ratio) F- test" at 95\% confidence level. The calculated $t$ and $\mathrm{F}$ - values were less than the theoretical values (Table 7) which indicated that there is no significant difference between both methods.

Table 6. Direct application of the suggested method for the determination of NIT in pharmaceutical forms.

\begin{tabular}{|c|c|c|c|c|c|}
\hline \multirow[b]{2}{*}{ Pharmaceutical form } & \multicolumn{2}{|c|}{ Conc. of NIT $\mu \mathrm{g} \mathrm{mL}$} & \multirow[b]{2}{*}{ Erel \% } & \multirow[b]{2}{*}{ Rec. \% } & \multirow[b]{2}{*}{ RSD \% } \\
\hline & Present & Found* & & & \\
\hline Zipex® tablets (5 mg & 100 & 101.1374 & +1.137 & 101.137 & 1.504 \\
\hline NIT) & 250 & 251.7321 & +0.693 & 100.693 & 0.636 \\
\hline
\end{tabular}

*Average of five determinations

Table 7. the evaluation of the official UV method with the proposed method.

\begin{tabular}{|c|c|c|}
\hline \multirow{2}{*}{ Preparation form } & Proposed method & official UV method \\
\hline & \multicolumn{2}{|c|}{ Recovery \% (average) } \\
\hline NIT( pure) & 100.4578 & 100.5417 \\
\hline NIT capsule $5 \mathrm{mg}$ & 100.9151 & 101.2417 \\
\hline$S^{2}$ & 0.10456 & 0.2450 \\
\hline$t *(4.303)$ & & \\
\hline $\mathrm{F}^{*}(161.4)$ & & \\
\hline
\end{tabular}

*theoretical value, $t$ has degree of freedom $=n_{1}+n_{2}-2=2$, F has degree of freedom $=n_{1}-1=1$.

\section{Conclusion:}

The proposed rFIA method found to be sensitive, simple, low cost, and offers the advantages of the rapidity with wide linearity range and high sampling rate. OCA is an excellent choice as reagent due to its readily available and sensitivity In addition, the proposed method is applicable for determinate NIT in pharmaceutical formulations in microgram concentration level. Moreover, the method did not need extraction or heating steps and FIA instruments are available in most laboratories.

\section{Conflicts of Interest: None.}

\section{References:}

1. The Indian pharmacopoeia.The Indian pharmacopoeia Commission, 2007. Vol.3.Ghaziabad, ED: The Indian Pharmacopoeia, pp: 834 .

2. British Pharmacopoeia on CD-ROM. 2007. Version $11,5^{\text {th }}$ ED. ,VOL.I\& II , copyright by System Simulation Ltd., the Stationery Office Ltd., London, pp: 303,832 .

3. Tanaka M, Suemaru K, Watanabe S, Cui R, Li B, Araki H. Comparison of short -and long-acting benzodiazepine-receptor agonists with different receptor selectivity on motor coordination and muscle relaxation following thiopental-induced anesthesia in mice. J.Pharm Sci. 2008,107:277-84.

4. Han S, Li X, Wei B. Silver nanoparticles enhanced chemiluminescence method for the determination of nitrazepam. J Anal Sci. 2014, 30:495-502.

5. Molaei K, Asgharinezhad AA , Ebrahimzadeh H, Shekari N,Jalilian N, Dehghani Z. Surfactant-assisted dispersive liquid-microextraction of nitrazepam and lorazepam from plasma and urine samples followed by high-performance liquid chromatography with UV analysis. J Sep Sci. 2015, 38:3905-3913.

6. Thangadurai S, Kanagraj B, Kulantheswaran M. Reversed-phase high-performance liquid chromatographic method for the simultaneous analysis of four benzodiazepines in pharmaceutical formulations. Malaysian J Forensic Sci. 2015:6-12.

7. Lee X, Shouji Y, Kumazawa T, Fujishiro M, Hasegawa T, Sato J, et.al. Rapid and highly sensitive analysis of benzodiazepines and tandospirone in human by automated on-line column switching UFLC-MS/MS. Legal Medicine. 2017,24: 36-55.

8. Tomita M, Okuyoma T. Application of capillary electrophoresis to the simultaneous screening and quantitation of benzpdiazepines J.Chromatogr.B.1996, 678(2):331-337.

9. Allen I, Box J, Comer A, Peake C, Tam Y. Multi wavelength spectrophotometric determination of acid dissociation constants of ionizable drugs. J. Pharm. Biomed.Anal., 1998,17(4-5):699-712.

10. Peiró C, Bose D, Dominguez M, Agusti G, Romero E. Direct injection micellar liquid chromatographic determination of benzodiazepines in serum. J. Chromatogr. B, 2002,780 (2): 241- 249.

11. Bakavoli M, Kaykhaii M. Quantitative determination of diazepam, nitrazepam and flunitrazepam in tablets using thin -layer chromatography densitometry technique. J.Pharm. Biomed. Anal. 2003,31(6): 11851189.

12. Gunnar T, Ariniemi K., Lillsunde P. Determination of 14 benzodiazepines and hydroxyl metabolites, zaleplon and zolpidem as tert-butyldimethylsilyl derivatives compared with other common silylating reagents in whole blood by gas chromatography-mass spectrometry. J. Chromatogr. B.2005, 818(2): 175 189. 
13. Honeychurch C, Smith C, Hart P. Voltametric behavior of nitrazepam and its determination in serum using liquid chromatography with redox mode dualelectrode detection. Anal. Chem. 2006,78(2): 416423.

14. Al-Shaker Y M. Imad Y. H. Spectrophotometric determination of Nitrazepam by coupling of Reduced Nitrazepam with N-(1naphthyl)ethylenediamine Dihidrochloride , Raf. Jour. Sci. 2011, 22(4):39-50.

15. Hussin M. T. Spectrophotometric determination of nitrazepam by coupling of its diazotized reduced form with m-aminophenol as coupling reagent, Raf. Jour. Sci. 2010, 21(4):123-140.

16. Deepakumari H.N. and Revanasiddappa H. D, , Spectrophotometric Estimation of nitrazepam in pure and in Pharmaceutical Preparations, Journal of Spectroscopy.2013,2013:1-8.

17. Maha T. Al-Obaidi, Theiaa Al-Sabha Thabit S. AlGhabsha. Spectrophotometric determination of nitrazepam and dapson using Vanillin reagent in pharmaceutical preparations. J.Edu. \& Sci., 2014, 27(1):43-57.

18. Revanasiddappa D, Mallegowda M, Deepakumari N, Vinary B. Spectrophotometric determination of nitrazepam and nimodipine in pure and tablet dosage forms Asian J. Pharm Clin. Res. 2011, 1(1):70-77.

19. Mariam J, Hind H. Determination of nitrazepam in pharmaceutical preparations using a solid -phase reactor-reverse flow injection analysis. Asian J Pharm Clin Res, 2018,11(7):487-492.

20. Sharma DK, Jasvir S, Pushap R. Spectrophotometric determination of propranolo hydrochloride and metopranol tartrate in pharmaceutical dosage forms, spiked water and biological fluids. Int J Pharm Pharm Sci 2018;10:107

21. Sevinç K, Emine G, Ebru Ç, Seda D, Koray D, Emre U, et.al Development of an automated flow injection analysis system for determination of phosphate in nutrient solutions. JSFA. 2018, 98(10): 3926-3934.

22. Poachanee N, Ornanong A, Saisunee L, Kontad O. Electrochemical flow injection determination of Ascorbic acid in fruit samples employing a Graphenepolyaniline electrode. IJCEA 2016,7( 2):142-145

23. Israa MJ, Sadeem SA. Flow injection spectrophotometric determination of Naringinie in Supplements using solid-phase reactor containing immobilized Manganese dioxide. Asian J Pharm Clin Res. 2018, Vol 11(8):473-478

24. Malik H A, Sadeem S A, Alsammarraie AMA. Determination of Clonazepam in pharmaceutical formulations by normal and reverse flow injection analysis coupled with solid-phase reactor containing MnO2 immobilized. JGPT. 2018: 10(06):411-419.

25. Hind HA. Cloud-point extraction and spectrophotometric determination of Clonazepam in pharmaceutical dosage forms. Bull. Chem. Soc. Ethiop. 2017, 31(3):373-382.

26. Cordenonsi LM, Sponchiado RM, Garcia CV, Raffin, R.P. , Schapoval EES. Study of flavonoids present in pomelo (Citrus Maxima) byDSC, UV-VIS, IR, 1H and 13C NMR and MS. Drug Anal Res, 2017,1(1):31-37.

\section{طريقة الحقن الجرياني العكوس والتقدير الطيفي للنايترازيبام في المستحضرات الصيدلانية باستخدام اورثو جوني حامض الكوماريك ككاثف كروموجيني جديد}

سديم صبحي عبد

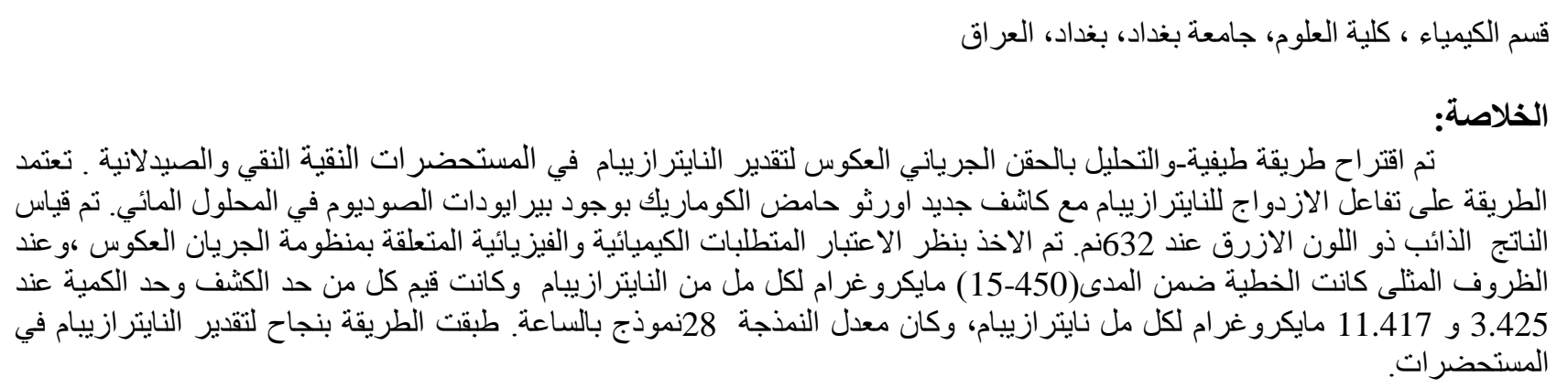

الكلمات المفتاحية: كاثف لوني، نايتر ازيبام، اورثو - حامض كوماريك، طريقة الحقن الجرياني العكوس 